\title{
Fabrication and Investigation of Mechanical Properties of SiC Particulate Reinforced AA5052 Metal Matrix Composite
}

\author{
Murlidhar Patel ${ }^{1 *}$, Sushanta Kumar Sahu ${ }^{2}$, Mukesh Kumar Singh ${ }^{1}$ \\ ${ }^{1}$ Department of Industrial and Production Engineering, Institute of Technology, Guru Ghasidas \\ Vishwavidyalaya (A Central University), Bilaspur, Chhattisgarh, India, 495009 \\ ${ }^{2}$ Department of Mechanical Engineering, National Institute of Science and Technology, Berhampur, Odisha, \\ India, 761008 \\ * Corresponding author email: murlidharpatel4@gmail.com
}

Received: 04 May 2020 / Revised: 19 June 2020 / Accepted: 27 June 2020 / Published: 06 July 2020

\begin{abstract}
In this present research particulate reinforced aluminium metal matrix composite is developed by using sand mould and liquid stir casting processing route in which AA5052 reinforced with 5 wt. \% SiC particulates of $63 \mu \mathrm{m}$ particle size. The density, porosity, micro-hardness, and compressive strength of SiC particulate reinforced AA5052 MMC were investigated and compared these properties with similar properties of unreinforced AA5052. The microstructure of the developed composite was also analysed by using optical microscopy, SEM, and XRD. Developed particulate reinforced Al metal matrix composite gives improved hardness and compressive strength as compared to the unreinforced AA5052. The addition of 5 wt. \% SiC particulates increases the density of AA5052.
\end{abstract}

Keywords: MMC, $\mathrm{SiC}, \mathrm{AMMC}$, compressive strength, hardness, density.

\section{Introduction}

Metal Matrix Composite (MMC) is an engineering material of present era which is developed by the macroscopic composition of reinforcement and metal matrix material. Ceramic materials i.e. alumina $\left(\mathrm{Al}_{2} \mathrm{O}_{3}\right)$, silicon carbide $(\mathrm{SiC})$, boron carbide $\left(\mathrm{B}_{4} \mathrm{C}\right)$ etc. are mostly used for reinforcement element in MMC to improve the mechanical as well as tribological properties the used metal matrix. MMCs have outstanding mechanical, tribological and excellent corrosive resistance properties as compared to presently used conventional materials [1-4]. Aluminium Metal Matrix Composite (AMMC) is a lightweight which have high strength to weight ratio and are mainly used for aerospace, automobiles, marine etc. [5-10]. AMMCs are isotropic in nature and rolling, forging, extrusion forming process can also be performed in it $[7,11,12]$. Particulate reinforced AMMCs give a good combination of mechanical, tribological and corrosion resistance properties at low cost which make it more attractive than conventional materials [13-16].

Cocen and Onel [17] have investigated the ductility and tensile strength of extruded SiC-p reinforced MMCs. By extrusion application in stir cast fabricated MMCs, disappear the cluster of SiC-p, reduce the porosity to very low levels and the yield tensile strength values are improved $40 \%$ approximately. The ductility of the as-cast composites is decreased with the increasing amounts of $\mathrm{SiC}-\mathrm{p}$, but yield strength and tensile strength of the as-cast composites increase with the volume fraction of $\mathrm{SiC}$-p upto $17 \%$ then decrease with further additions of reinforcement. Sahin [18] has prepared and analysed the mechanical properties of squeeze cast SiC-p reinforced AMMCs. He observed hardness, density and porosity of AMMCs are increase when the wt. $\%$ of $\mathrm{SiC}-\mathrm{p}$ increases. The functionally graded centrifugal cast $\mathrm{Al} / \mathrm{SiC}-\mathrm{p}$ MMCs fabricated and characterized by El-Galy et al. [19]. They observed in the cast tubes, SiC-p concentrations and hardness in the outer zone 
reach its maximum value and followed by a gradual decrease in concentrations and hardness in the direction of inner diameter. With increase in wt. $\%$ of SiC-p, proportionally increase in outer zone hardness but beyond 10 wt. \% SiC-p the increasing rate is decreases slightly. They found that the ultimate tensile strength is proportional to the percentage of SiC-p and inversely proportional to the size of the particles. The tensile strength is increases linear up to $10 \mathrm{wt}$. \% $\mathrm{SiC}-\mathrm{p}$ and the increase rate is lower afterwards up to 15 wt. \% SiC-p. Venkataraman and Sundararajan [20] have investigated the tensile strength behaviour of SiC-p reinforced AMMCs and they also reported that the tensile strength increases but tensile density decreases when the volume fraction of $\mathrm{SiC}-\mathrm{p}$ is increase in $\mathrm{Al}$ matrix. Ozben et al. [21] have examined hardness and density of AMMCs increased with increase in reinforcement ratio, but impact toughness decreased. They also find tensile strength increased upto 10 wt. \% of SiC-p reinforced and decreased when 15 wt. $\%$ of SiC-p reinforcement used. Rao [22] has done an experimental investigation on mechanical properties of Al7075/SiC-p MMC and he also found that by increase in SiC-p size and wt. \% considerably enhanced the tensile strength and hardness of the AMMC but the ductility of the AMMC is decreased.

Ozden et al. [23] have investigated the impact behaviour at different temperature i.e. $-176^{\circ} \mathrm{C}$, $21^{\circ} \mathrm{C}, 100^{\circ} \mathrm{C}, 200^{\circ} \mathrm{C}$ and $300^{\circ} \mathrm{C}$ of SiC-p $(167 \mu \mathrm{m}$ and $511 \mu \mathrm{m})$ reinforced AMMCs with hot extrusion ratio of 13.63:1 and 19.63:1. They observed impact toughness of ductile $\mathrm{Al}$ alloy matrix decreases with the addition of $\mathrm{SiC}-\mathrm{p}$ as reinforcement. The impact toughness of the AMMC slightly improved with increased particle size and the hot extrusion ratio, but artificial ageing decreased the impact toughness of the both $\mathrm{Al}$ alloys and AMMCs. The test temperature were not affected the impact behaviour of unreinforced $\mathrm{Al}$ alloy and $\mathrm{SiC}-\mathrm{p}$ reinforced AMMCs. Meena et al. [24] have investigated the mechanical properties of the developed stir cast $\mathrm{Al} / \mathrm{SiC}-\mathrm{p}$ MMCs. They observed proportionality limit, upper \& lower yield point, ultimate tensile strength, breaking strength, hardness and density increases with the increase in $\mathrm{SiC}$ particulate size (220 mesh, 300 mesh, 400 mesh) and weight fraction $(5 \%, 10 \%, 15 \%$ and $20 \%)$ of SiC-p, but $\%$ elongation and $\%$ reduction in area decreases with the increase in particulate size a\& wt. $\%$ of SiC-p. Impact strength decreases with the increase in SiC-p size and increases with the increase in wt. \% of SiC-p. For fabrication of AA5052/SiC-p MMC, the friction stir processing (FSP) route is used by Dolatkhah et al. [25]. In this investigation, $5 \mu \mathrm{m} \& 50 \mathrm{~nm} \mathrm{SiC}-\mathrm{p}$ were used to fabricate surface layer composite. They reported that the SiC-p reinforcement, higher number of FSP passes, shifting the direction of tool rotation between passes and decrease of $\mathrm{SiC}$ particles size, enhance the hardness and wear resistance properties of the AA5052.

In this study the microstructure of the stir cast AA5052/SiC-p MMC, effect of SiC-p on the density, porosity, micro-hardness and compressive strength of the AA5052 have been investigated and the microstructure of the developed MMC is also characterized using optical microscopy, SEM and XRD.

\section{Experimental Studies}

\subsection{Materials and Method}

The materials chosen for the present work is $5 \mathrm{xxx}$ series of $\mathrm{Al}$ alloy in which principal alloying element is $\mathrm{Mg}$. The $5 \mathrm{xxx}$ series is mainly used in marine applications due to its high corrosion resistance property, but when the $\mathrm{Mg}$ content present in the $\mathrm{Al}$ is greater than $3 \%$ then problem of stress corrosion cracking occurs at temperature above the $63^{\circ} \mathrm{C}$ [26]. So in this present work AA5052 has been chosen for the experiment due to its excellent corrosion resistance property to seawater and industrial atmosphere with $\mathrm{Mg}$ content less than 3\%. It has very good weldability and good cold formability property. AA5052 is used for hospital and medical equipment, fan blades, hydraulic tubes, fuel tanks, pressure vessels, rivets etc. One of the major drawbacks of these alloys is their low strength. By improving the strength of these alloys, the functionality of these alloys can be broadened and used in many more applications. For the present work 5 wt. $\%$ of $\mathrm{SiC}$ particles are 
Murlidhar Patel et al., J. Mod. Mater:; Vol. 7, Issue 1, pp: 26-36, 2020

used as reinforcement material due to their high hardness, high modulus of elasticity to improve the mechanical properties of AA5052. The particle size of the used SiC-p is $63 \mu \mathrm{m}$. The chemical compositions of AA5052 are listed in Table 1 . The stir casting processing route is used for the synthesis of AMMC for present work. The required amount of AA5052 was taken in graphite crucible and set in a resistance heating furnace then the alloy was melt at $800^{\circ} \mathrm{C}$ as shown in Figure 1.
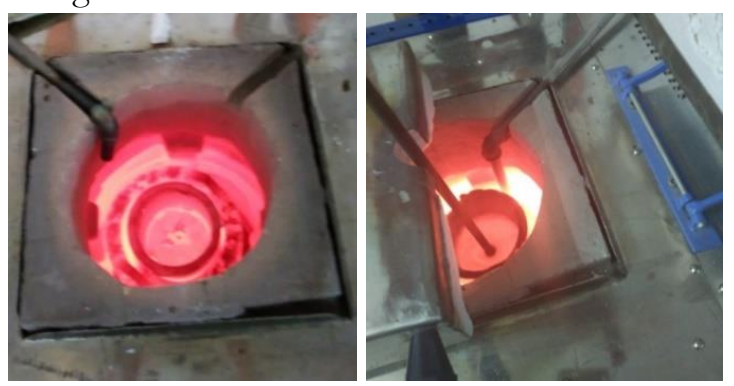

Figure 1: Melting of AA5052 in resistance furnace

Dross product formed and floating over the molten alloy was firstly removed, then the molten AA5052 was degassed by using solid hexachloro ethane $\left(\mathrm{C}_{2} \mathrm{Cl}_{6}\right)$ tablet, because the molten AA5052 reacts with atmospheric oxides and degrades properties by oxidation $[27,28]$. The calculated quantity of SiC-p (5 wt. \%) was preheated at $900^{\circ} \mathrm{C}$ for $1 \mathrm{hr}$ in an another electric resistance furnace to (i) reduce the temperature gradient and increase wettability between the molten alloy and particle by removing the adsorbed gases and moisture from the particles and (ii) to facilitate formation of thin $\mathrm{SiO}_{2}$ layer on the SiC-p surface [8]. The preheating of $\mathrm{SiC}$ is necessary; because without preheating, $\mathrm{SiC}$ would react with $\mathrm{Al}$ and form $\mathrm{Al}_{4} \mathrm{C}_{3}$ at the interface of $\mathrm{Al}$ and SiC. This would degrade the reinforcement strength and increase the corrosion susceptibility the $\mathrm{Al}$ alloy [29].

The reactions occur with or without preheating of $\mathrm{SiC}$ with $\mathrm{Al}$ are given in the equation (1) and equation (2) respectively.

Reaction of without preheated $\mathrm{SiC}$ with $\mathrm{Al}$ :

$$
4 \mathrm{Al}+3 \mathrm{SiC} \rightarrow \mathrm{Al}_{4} \mathrm{C}_{3}+3 \mathrm{Si}
$$

Reaction of preheated $\mathrm{SiC}$ with $\mathrm{Al}$, in which a thin $\mathrm{SiO}_{2}$ layer formed on the $\mathrm{SiC}$ surface:

$4 \mathrm{Al}+3 \mathrm{SiO}_{2} \rightarrow 2 \mathrm{Al}_{2} \mathrm{O}_{3}+3 \mathrm{Si}$

The preheated $\mathrm{SiC}$ particulates are packed in $\mathrm{Al}$ foil then added into the molten AA5052. With the help of graphite stirrer, stirred the composite slurry for $10 \mathrm{~min}$. at $600 \mathrm{rpm}$ after that the composite slurry in Gr crucible was taken from the furnace with the help of tong and poured into prepared cavities in sand mould of required shape as shown in Figure 2(a), poured composite slurry into the sand mould is shown in Figure 2(b) and the developed SiC-p reinforced AA5052 MMC is shown in Figure 2(c).

Table 1: Chemical composition of AA5052 by weight percentage

\begin{tabular}{|l|l|l|l|l|l|l|l|l|}
\hline Elements & Mg & Cr & Fe & Mn & Si & Cu & Zn & Al \\
\hline \% by weight & 2.5 & 0.25 & 0.35 & 0.1 & 0.2 & 0.1 & 0.1 & Remaining \\
\hline
\end{tabular}
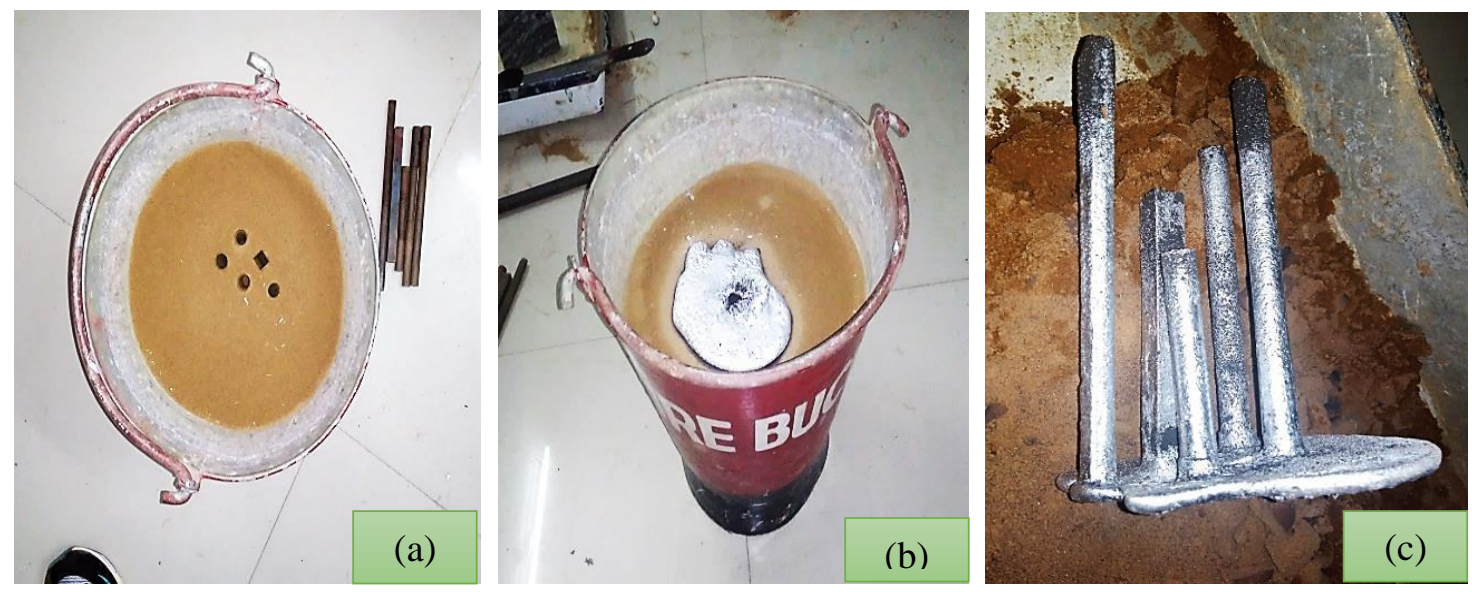

Figure 2: (a) Cavities prepared for casting (b) Poured composite slurry in cavities (c) Developed AA5052 +5 wt. \% SiC-p MMC 
The fabricated as-cast AA5052 and AA5052 + 5 wt. \% SiC-p MMC are shown in Figure 3.

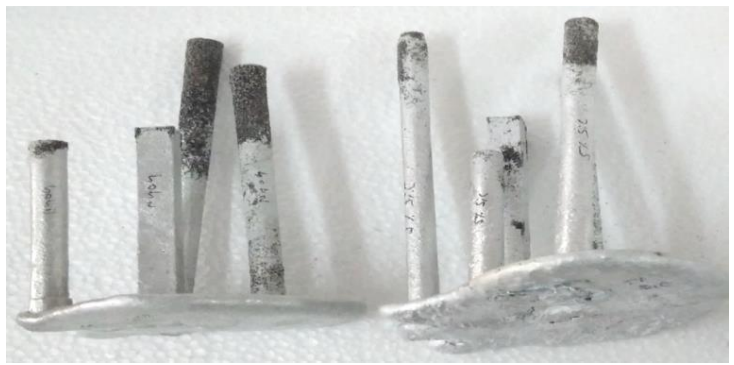

Figure 3: Developed as-cast AA5052 and AA5052/SiC-p MMC

\subsection{Microstructure Characterization}

For the microstructural characterization of the AA5052 + 5 wt. $\%$ SiC-p MMC, $10 \times 10 \times 3 \mathrm{~mm}^{3}$ test samples was prepared from the middle section of the casted compositions as shown in Figure 4. The test samples were matallographically polished upto 2000 grade emery paper and cleaned with acetone to carry out microstructural characterization using ZEISS AxioCam ERc 5s Optical microscopy at 5x magnification, ZEISS EVO 18 SEM equipped with the Oxford EDS system (INCA 250 EDS with X-MAX 20mm Detector) and X'pert Powder - Multifunctional XRD from PANalytical.

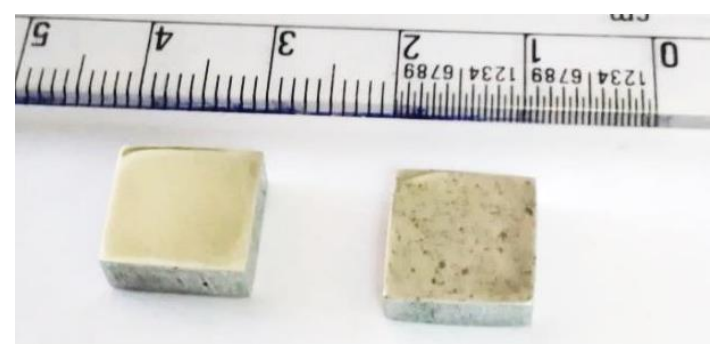

Figure 4: Test samples for microstructure characterization

\subsection{Mechanical Characterization}

\subsubsection{Density and Porosity Measurement}

The theoretical density of the as-cast AA5052 and the developed AA5052 + 5 wt. \% SiC-p MMC was calculated from the rule of mixture formula, given by following equation (3) [2]. The density was calculated experimentally by applying Archimedes' principle and finally the density of the sample of casted compositions was calculated by using equation (4). The percentage of porosity presented in the as-cast AA5052 and the developed AA5052 + 5 wt. \% SiC-p MMC was calculated by using the equation (5) [30].

$$
\begin{gathered}
\frac{1}{\rho_{c}}=\frac{W_{r}}{\rho_{r}}+\frac{W_{m}}{\rho_{m}} \\
\rho_{c}=\frac{m_{1}}{m_{2}-m_{3}} \times \rho_{H_{2} O}
\end{gathered}
$$

$$
\begin{aligned}
& \text { Porosity (\%) } \\
& =\left[1-\frac{\text { Measured density }}{\text { Theoretical density }}\right] \times 100
\end{aligned}
$$

Where: ' $\rho_{c}$ ', ' $\rho_{r}$ ' and ' $\rho_{m}$ ' is the density of composite or alloy, reinforcement and matrix respectively. ' $W_{r}$ ' \& ' $W_{m}$ ' is the weight fraction of the reinforcement and the matrix respectively. ' $m_{1}$ ' is the mass of sample in air ' $m_{2}$ ' is the mass of sample in air with stand, ' $m_{3}$ ' is the mass of sample in water with stand and ' $\rho_{\mathrm{H}_{2} \mathrm{O}}$ ' is the density of distilled water (at $293 \mathrm{~K}$ ) is 0.9982 $\mathrm{g} / \mathrm{cm}^{3}$

\subsubsection{Micro-hardness Test}

Hardness test of test samples of the developed compositions was carried out according to ASTM E384 by using LECO LM248AT Micro hardness Tester as shown in Figure 5. Dimensions of the prepared test samples were $15 \times 10 \times 10 \mathrm{~mm}^{3}$ and were metallographic polished by 600 grit $\mathrm{SiC}$ waterproof abrasive paper for conducting the micro-hardness test. Micro-hardness test was performed at room temperature using a highly polished, pointed, square-based pyramidal diamond indenter with face angles of $136^{\circ}$ and load of $300 \mathrm{gf}$ applied for dwell time of $10 \mathrm{sec}$ on the polished surface of the test sample. The value of the calculated hardness was shown digitally. Micro-hardness measurement was done on each casted composition by measurements taken at four different points of each sample to assess its reproducibility. The Micro-hardness value is shown by Vickers hardness number $(H V)$ and theoretically the value of Vickers hardness number is calculated by the equation (6) [31].

$$
H V=\frac{2 P \sin \left(\frac{\alpha}{2}\right)}{d^{2}}=\frac{1.8544 P}{d^{2}}
$$


Murlidhar Patel et al., J. Mod. Mater:; Vol. 7, Issue 1, pp: 26-36, 2020

Where: 'P' = Applied load in kgf, ' $\alpha$ ' = face angle of the diamond indenter $=136^{\circ},{ }^{\prime} \mathrm{d}$ ' $=$ mean diagonal of impression in $\mathrm{mm}$.
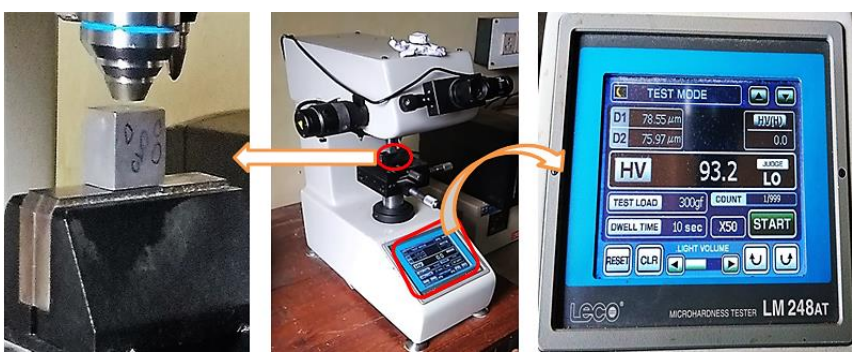

Figure 5: Micro-hardness test carried out according to ASTM E384

\subsubsection{Compression Test}

The standard test samples were prepared into sizes of $11 \mathrm{~mm}$ diameter and $26 \mathrm{~mm}$ length to carry out the compression test. The test samples were fixed in the computerized universal testing machine of INSTRON SATEC $600 \mathrm{kN}$ as shown in Figure 6 to conduct compression test by choosing the compression fixture. The movable jaws were properly adjusted so as to keep gauge length of $26 \mathrm{~mm}$. The maximum capacity of the UTM INSTRON SATEC $600 \mathrm{kN}$ was $600 \mathrm{kN}$. $600 \mathrm{KN}$ Models of INSTRON are ideal for high capacity tension, compression, flex and shear testing [32]. The compressive load is gradually applied with cross head speed of $2 \mathrm{~mm} /$ minute along principal material direction. The test sample broke after the applied load reached ultimate value.
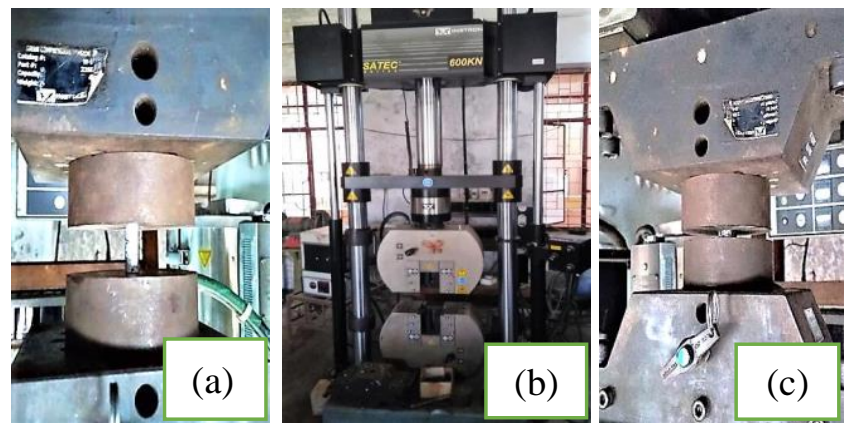

Figure 6: (a) Sample before compression test (b) Used INSTRON SATEC UTM (c) Sample after compression test

\section{Results and Discussion}

\subsection{Microstructure}

The optical micrographs of as-cast AA5052 and stir cast AA5052 + 5SiC-p MMC are shown in Figure 7. Figure $7(\mathrm{a})$ and Fig. 7(b) show the optical microstructure of as-cast AA5052 and stir cast AA5052 + 5SiC-p MMC respectively. Figure 7 (c) shows the SEM image of the sample of AA5052 + 5SiC-p MMC. These figures clearly indicate that the voids or pores not present in the developed compositions.
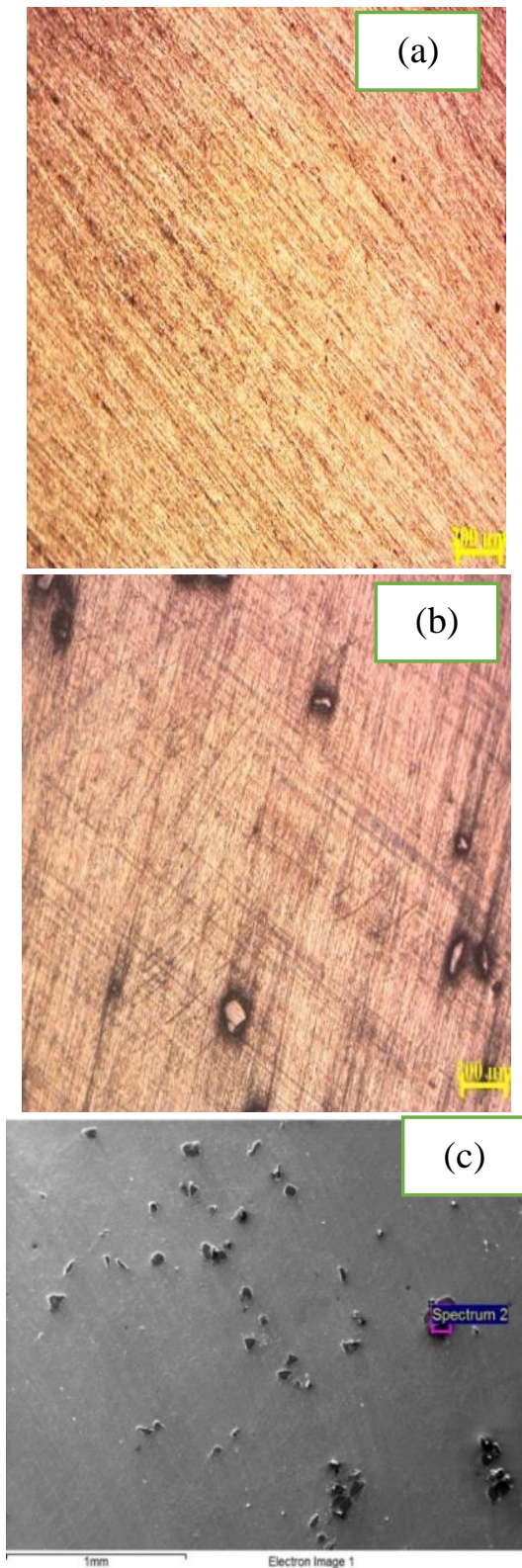

Figure 7: Micrograph of the developed compositions: (a) Optical micrograph of AA5052 (b) Optical micrograph of AA5052/SiC-p MMC (c) SEM image of AA5052/SiC-p MMC 
Fabrication and Investigation of Mechanical Properties of SiC Particulate Reinforced AA5052 Metal Matrix Composite

By analysis of Fig. 7(b) \& 7(c) it is confirmed the presence of $\mathrm{SiC}$ particulates in the AA5052 matrix. The distribution of the SiC-p are fairly uniform but certain places they are agglomerate or clustered as shown in Fig. 7(c), this is due to simultaneously added of SiC-p in the molten AA5052 matrix at the time of stirring. In both ascast AA5052 and stir cast AA5052 + 5SiC-p MMC no any pores existed due to improved wettability of preheated $\mathrm{SiC}$ particulates and well casting. Due to absence of cavities either at interfaces or in matrix, a good bonding between the AA5052 matrix and $\mathrm{SiC}$ particulate was obtained.

An X-ray diffraction pattern of developed AA5052 + 5SiC-p MMC is shown in Fig. 8. XRD of these composites was carried out using $\mathrm{CuK} \alpha$ radiation $(\lambda=1.54056 \AA$ ). The diffraction angle varies from $0^{\circ}-100^{\circ}$. XRD data of AA5052+ 5SiC-p MMC was analysed by 'MAUD 2.8' software with the help of 'Crystallography Open Database (COD)'. The profile of the $\mathrm{Al}, \mathrm{SiC}$, and $\mathrm{Al}_{2} \mathrm{O}_{3}$ constituents are matching with the profile of XRD and the type of crystal system, density and percentage amount of these constituent are tabulated in the Table 2. From XRD analysis of the developed composite, confirmed that the presence of $\mathrm{SiC}$.
Table 2: XRD analysis of AA5052 + SiC-p MMC

\begin{tabular}{|c|c|c|c|c|}
\hline $\begin{array}{c}\text { S. } \\
\text { N. }\end{array}$ & $\begin{array}{c}\text { Element/Com } \\
\text { pound }\end{array}$ & $\begin{array}{c}\text { Cryst } \\
\text { al } \\
\text { Syste } \\
\mathbf{m}\end{array}$ & $\begin{array}{c}\text { Calcul } \\
\text { ated } \\
\text { Density } \\
\left(\mathbf{g} / \mathbf{c m}^{\mathbf{3}}\right)\end{array}$ & $\begin{array}{c}\text { Amo } \\
\mathbf{u n t} \\
(\boldsymbol{\%})\end{array}$ \\
\hline 1. & Aluminium & Cubic & 2.715 & $\begin{array}{c}92.63 \\
9\end{array}$ \\
\hline 2. & $\begin{array}{c}\text { Silicon } \\
\text { Carbide }\end{array}$ & Cubic & 3.240 & 5.212 \\
\hline 3. & $\begin{array}{c}\text { Aluminium } \\
\text { Oxide }\end{array}$ & $\begin{array}{c}\text { Trigo } \\
\text { nal }\end{array}$ & 3.991 & 2.148 \\
\hline
\end{tabular}

\subsection{Density and Porosity}

It is noted that from Fig. 9 both measured and theoretical density increase with the addition of $\mathrm{SiC}$ particulates into the AA5052 matrix. This is due to the higher density of $\mathrm{SiC}\left(3100 \mathrm{~kg} / \mathrm{m}^{3}\right)$ as compared to the density of AA5052 (2680 $\left.\mathrm{kg} / \mathrm{m}^{3}\right)$. From the Figure 9, it may also be concluded that both the measured as well as theoretical density of the casted compositions are in-line with each other and indicates the suitability of stir casing. The measured density of AA5052/SiC-p MMC is $0.8 \%$ higher than the unreinforced AA5052 matrix. A similar increases in density with the addition of SiC particulates in $\mathrm{Al}$ alloys was found by Sahin [18], Meena et al. [24], Ozben et al. [21] and Sujan et al. [33].

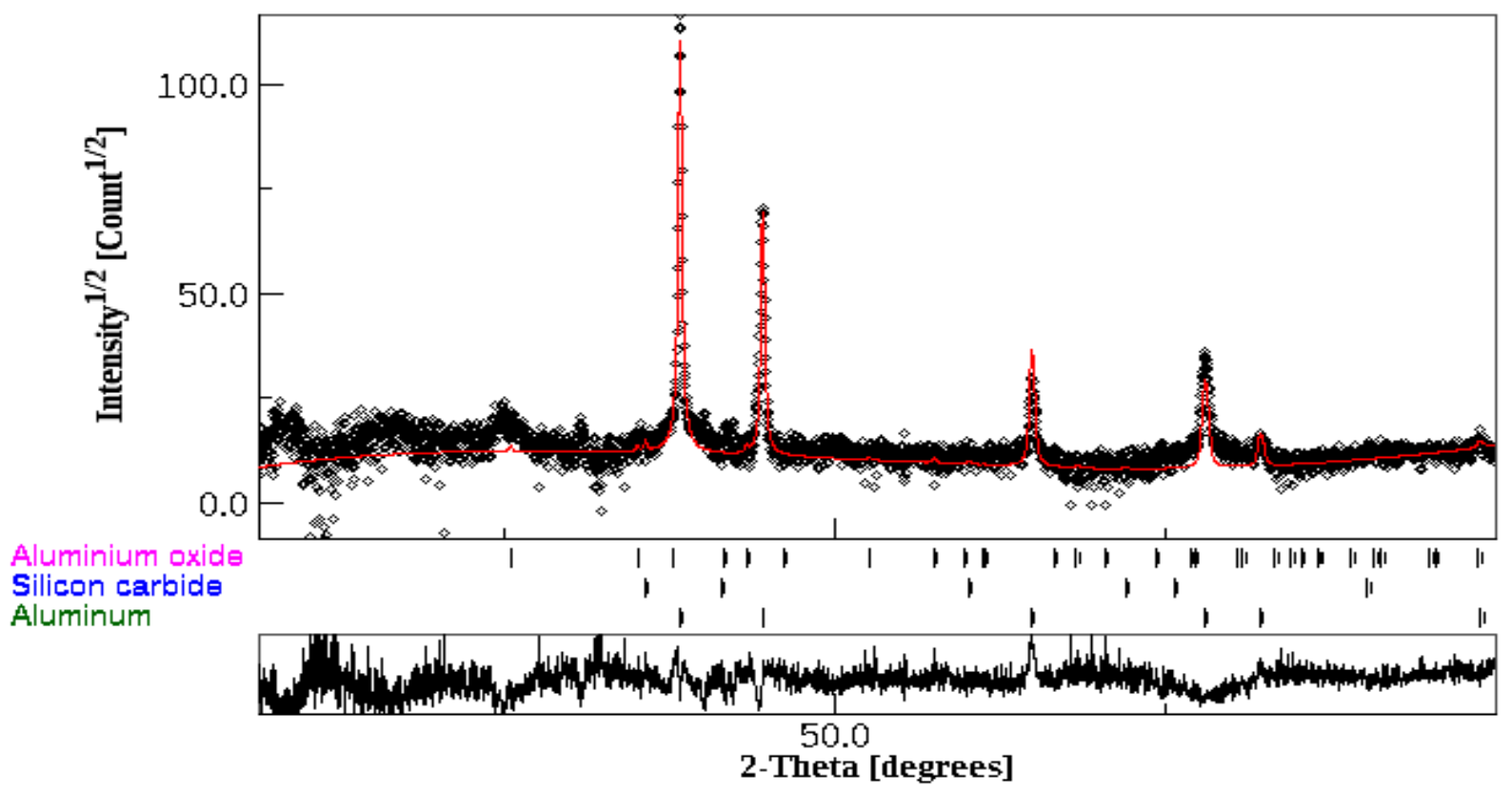

Figure 8: X-ray diffraction pattern of AA5052 + SiC-p MMC 


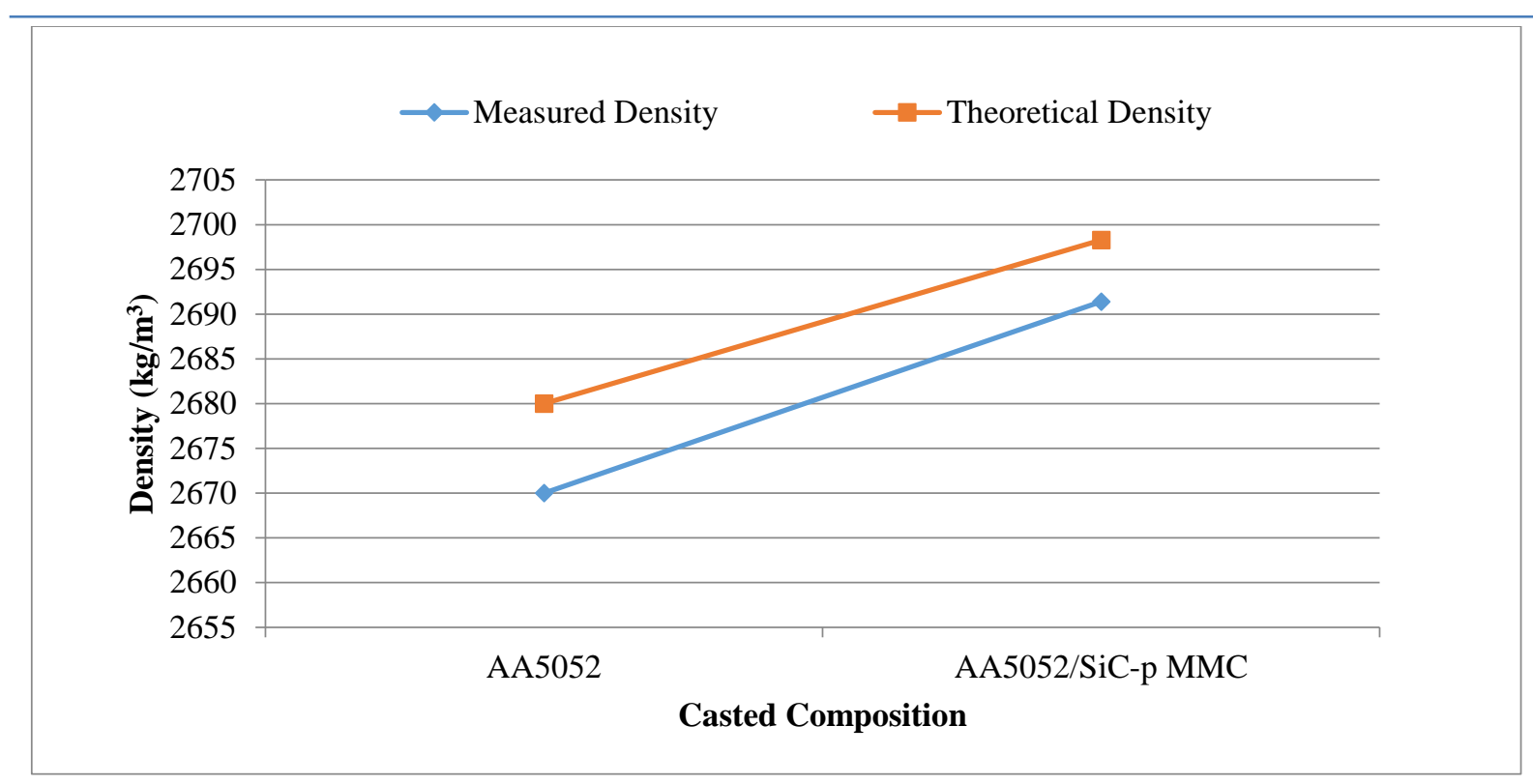

Figure 9: Variation in measured and theoretical density of developed compositions

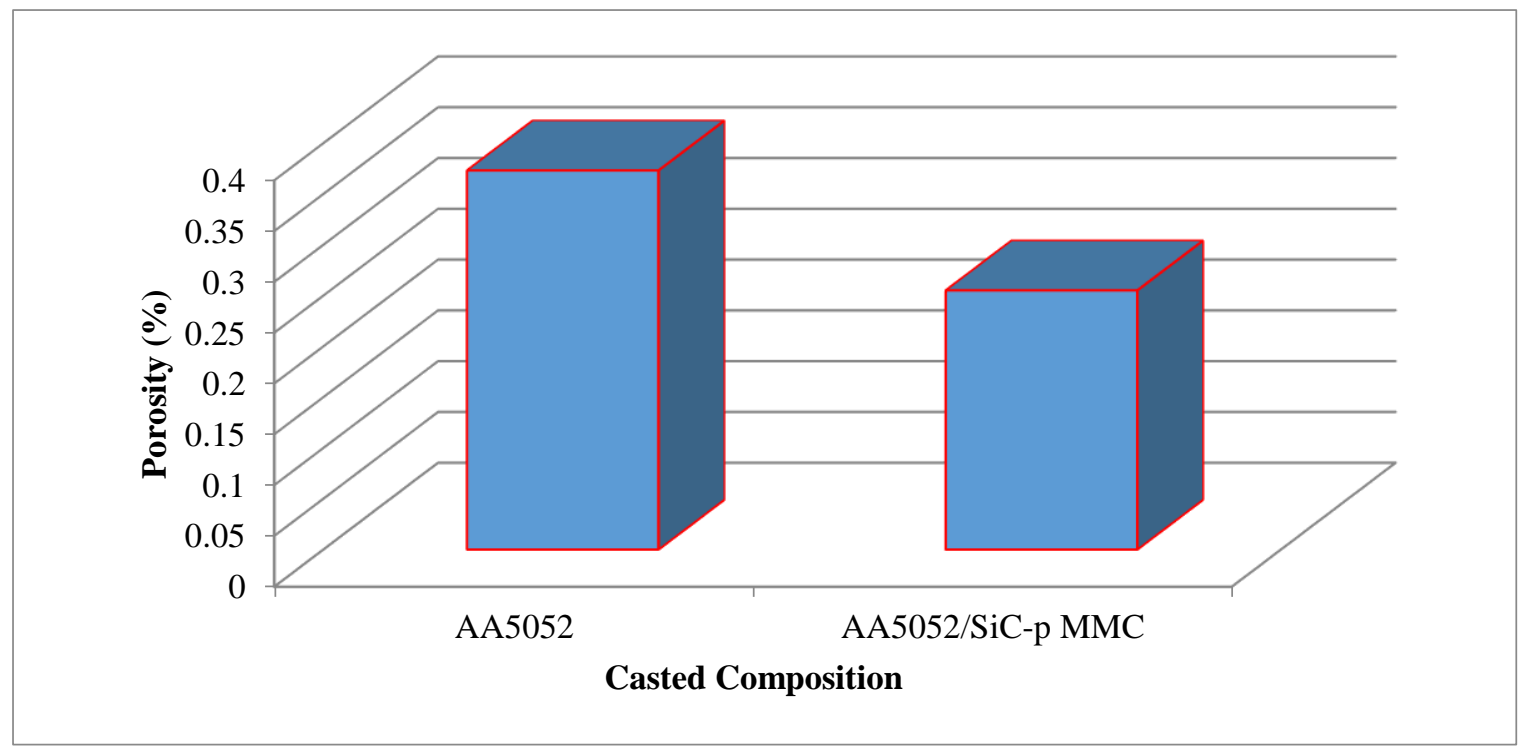

Figure 10: Percentage porosity presented in casted compositions

The percentage porosity presented in both the ascast AA5052 and AA5052/SiC-p MMC is shown in Fig. 10. The difference between measured and theoretical density indicates that the presence of porosity in the casted compositions and it can also be affecting the performance of cast compositions. It is also concluded that from Fig. 10 , the porosity presented in as-cast AA5052 and AA5052/SiC-p MMC is very small $(<0.5 \%)$ due to the well casting process.

\subsection{Micro-hardness}

Micro-hardness measurement at four different points of the developed compositions is listed in Table 3 and the average hardness value of each composition is also plotted in Fig. 11. From Fig. 11 , it is observed that the micro-hardness of the developed composites is higher than the unreinforced AA5052. The presence of hard SiC particulates increases the value of micro-hardness of the composite. 5\% SiC-p addition in AA5052 increases the hardness from $66.725 \mathrm{HV}$ to 
Fabrication and Investigation of Mechanical Properties of SiC Particulate Reinforced AA5052 Metal Matrix Composite

93.225HV. Dolatkhah et al. [25] have been reported that the addition of SiC-p to AA5052 led to increase in micro-hardness upto $55 \%$. With the addition of hard $\mathrm{SiC}$ particulates in AA5052 matrix, results in $39.72 \%$ improvement in the micro-hardness.

Table 3: Micro-hardness of the developed compositions

\begin{tabular}{|c|c|c|c|c|c|c|}
\hline $\begin{array}{c}\text { S. } \\
\text { N. }\end{array}$ & $\begin{array}{c}\text { Cast } \\
\text { Composition }\end{array}$ & \multicolumn{4}{|c|}{$\begin{array}{c}\text { Micro-hardness value } \\
\text { (HV) }\end{array}$} & Average \\
(HV)
\end{tabular}

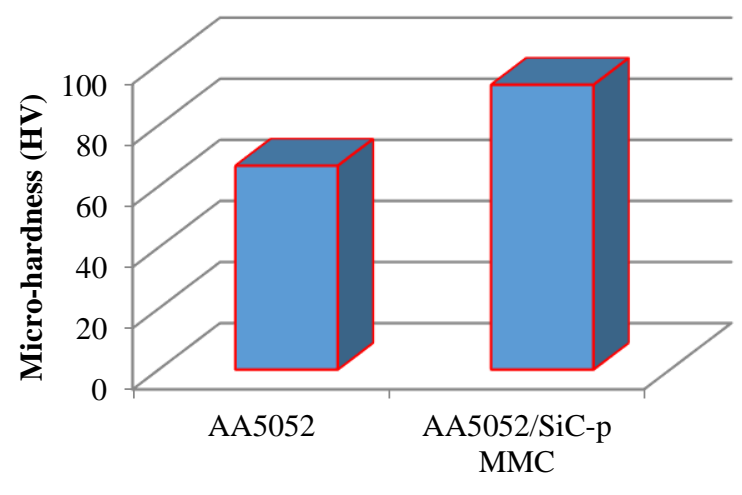

Developed Composition

Figure 11: Average micro-hardness of the developed compositions

\subsection{Compressive Strength}

Compressive strength of particulate reinforced AMMCs are mainly decided by the reinforcement type and their content in matrix. So the variations in compressive strength of AA5052 with the addition of $5 \% \mathrm{SiC}$ particulate reinforcement obtained from the compression test is plotted in Fig. 12. The ultimate compressive strength of AA5052 increases from $819 \mathrm{MPa}$ to $890 \mathrm{MPa}$ with the addition of SiC-p in it, because $\mathrm{SiC}$ has compressive strength of $3.9 \mathrm{GPa}$, which is approximately 24 times higher than the compressive strength of AA5052, hence SiC impart $8.5 \%$ higher compressive strength to the developed AA5052/SiC-p MMC. In the case of SiC-p reinforced AMMC, Mahendra \& Radhakrishna [27] also found similar improvement in result. With the addition of $5 \mathrm{wt}$.
$\%$ of SiC-p in AA5083 matrix Idrisi et al. [34] found the compressive strength increases by $4.7 \%$.

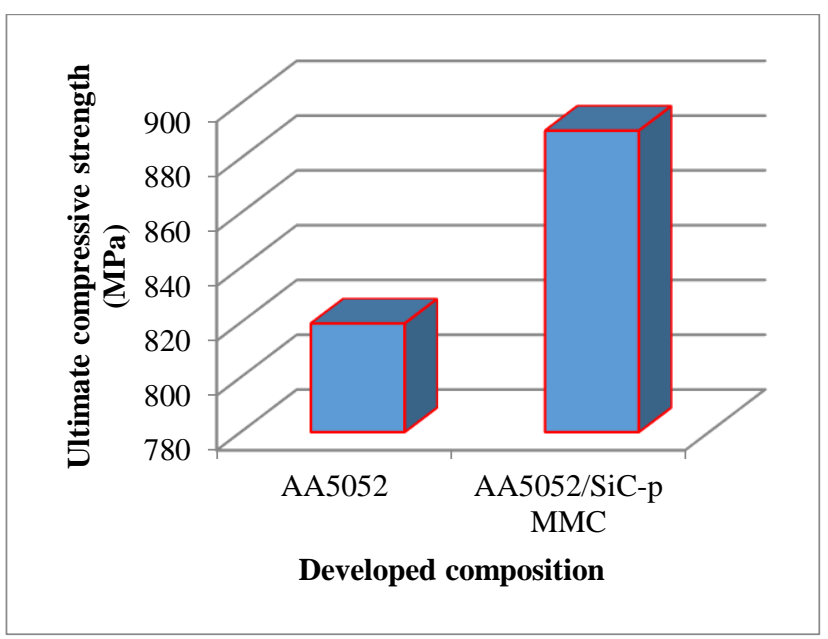

Figure 12: Compressive strength of the casted compositions

Load vs. displacement curve for unreinforced AA5052 is shown in Fig. 13 (a). The maximum load obtained for the sample is $77,894.79 \mathrm{~N}$ and analogous to this maximum force, compressive strength calculated is $819.66 \mathrm{MPa}$. Figure 13(b), shows the load-displacement curve for AA5052/SiC-p MMC.
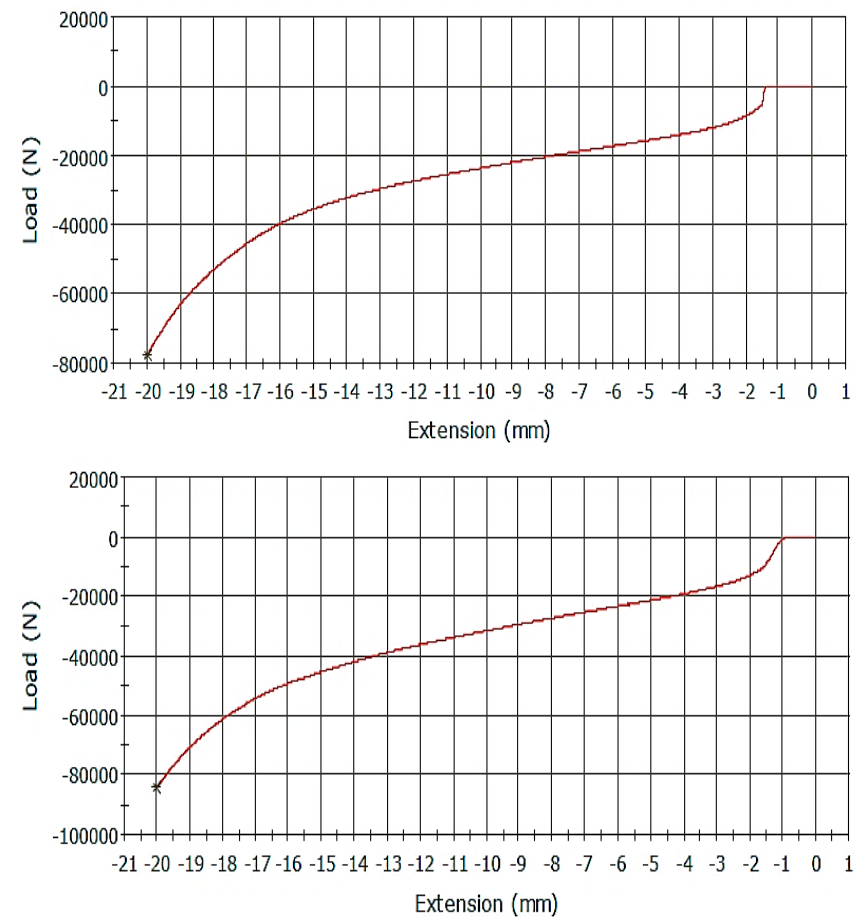

Figure 13: Load vs. displacement curve for $(a)$ AA5052 composition (b) AA5052/SiC-p MMC 
The maximum load obtained for the sample is $84,584.84 \mathrm{~N}$ and analogous to this maximum force, compressive strength calculated is 890.06 $\mathrm{MPa}$. Comparative observation of compressive strength between the sample of AA5052 and AA5052/SiC-p MMC compositions reveals that the dispersion of 5 wt. \% SiC-p in AA5052 matrix is responsible for increase in compressive strength.

High hardness of the MMC is also required to improve the wear resistance properties, most of the researchers are also working on to improve the wear resistance properties of AMMCs to implement these materials on the hydraulic field and also try to decreases the density of the AMMCs to implement in the field of aerospace, automobile [35]. Power saving and noise reduction in the field of aerospace and automobile are very essential requirement. Lightweight AMMCs are used for power saving and noise reduction in the field of Automobiles [36, 37]. In this research work the developed AMMC having high hardness and strength and this can be used in the hydraulic field like slurry pump impeller and pump casing.

\section{Conclusions}

In this research, the AA5052 matrix has been reinforced with $5 \mathrm{wt} . \% \mathrm{SiC}$ particulates of $63 \mu \mathrm{m}$ particle size by using stir casting liquid processing technique and it is concluded that the optical and SEM micrographs of the AA5052/SiC-p MMC show the uniform distribution of the $\mathrm{SiC}$ particles and from XRD analysis confirm the presence of $\mathrm{SiC}$ in AA5052 matrix. The density of the AA5052 increases up to $0.8 \%$ with the addition 5 wt. $\% \mathrm{SiC}$ particulates. Very less percentage $(<0.5 \%)$ of porosity present in the developed compositions, which are $0.37 \%$ and $0.26 \%$ for the as-cast AA5052 and AA5052/SiC-p MMC respectively. With the addition of the $\mathrm{SiC}$ particulates into the AA5052 matrix, the microhardness and compressive strength of the AA5052 are improved by $39.72 \%$ and $8.5 \%$ respectively. Due to improved hardness and good compressive strength of the AA5052/SiC-p MMC can be applicable for the various I.C. engines parts i.e. connecting rod, cylinder blocks. The developed MMC can also replace the conventional $\mathrm{Al}$ alloy material used for fan blades, medical equipment due to its advantageous properties. It is also applicable for the aircraft and aerospace industries in the strength points of view but its implementation is limited due their increase in the density with the addition of $\mathrm{SiC}$ particulates. With the increase in the weight fraction and particle size of $\mathrm{SiC}$ in AA5052 matrix these experiments can also be done in the future.

\section{Declarations}

\subsection{Acknowledgements}

The authors are highly grateful to the Department of Mechanical Engineering of National Institute of Science and Technology, Berhampur, Odisha, India for providing the experimentation facilities for this research work.

\subsection{Competing Interests}

No any potential conflict of interest exists in this publication.

\section{How to Cite this Article:}

M. Patel, S. Sahu, and M. Singh, "Fabrication and Investigation of Mechanical Properties of SiC Particulate Reinforced AA5052 Metal Matrix Composite", J. Mod. Mater., vol. 7, no. 1, pp. 26-36, Jul. 2020. https://doi.org/10.21467/jmm.7.1.26-36

\section{References}

[1] R. M. Jones, Mechanics of composite materials, Second Edi. CRC press, 1998.

[2] A. K. Kaw, Mechanics of composite materials. CRC press, 2006.

[3] T. Ozben, E. Kilickap, C. Orhan, and O. Çakir, "Investigation of mechanical and machinability properties of SiC particle reinforced Al-MMC," J. Mater. Process. Technol., vol. 198, no. 1-3, pp. 220-225, 2008. https://doi.org/10.1016/j.jmatprotec.2007.06.082

[4] M. Patel, S. K. Sahu, and M. K. Singh, "Abrasive wear behavior of SiC particulate reinforced AA5052 metal matrix composite," Mater. Today Proc., 2020. https://doi.org/10.1016/j.matpr.2020.03.572

[5] M. Patel, B. Pardhi, S. Chopara, and M. Pal, "Lightweight Composite Materials for Automotive - A Review," Int. Res. J. Eng. Technol., vol. 5, no. 11, pp. 41-47, 2018.

[6] Y. C. Feng, L. Geng, P. Q. Zheng, Z. Z. Zheng, and G. S. Wang, "Fabrication and characteristic of Al-based hybrid composite reinforced with tungsten oxide particle and aluminum borate whisker by squeeze casting," Mater. Des., vol. 29, no. 10, pp. 2023-2026, 2008. https://doi.org/10.1016/j.matdes.2008.04.006

[7] Z. Z. Chen and K. Tokaji, "Effects of particle size on fatigue crack initiation and small crack growth in $\mathrm{SiC}$ 
particulate-reinforced aluminium alloy composites," Mater. Lett., vol. 58, no. 17-18, pp. 2314-2321, 2004. https://doi.org/10.1016/j.matlet.2004.02.034

[8] K. M. Shorowordi, T. Laoui, A. S. M. A. Haseeb, J. P. Celis, and L. Froyen, "Microstructure and interface characteristics of $\mathrm{B} 4 \mathrm{C}, \mathrm{SiC}$ and $\mathrm{Al} 2 \mathrm{O} 3$ reinforced $\mathrm{Al}$ matrix composites: a comparative study," J. Mater. Process. Technol., vol. 142, no. 3, pp. 738-743, 2003. https://doi.org/10.1016/S0924-0136(03)00815-X

[9] M. Patel, A. Kumar, B. Pardhi, and M. Pal, "Abrasive , Erosive and Corrosive Wear in Slurry Pumps - A Review,” Int. Res. J. Eng. Technol., vol. 7, no. 3, pp. 2188-2195, 2020.

[10] M. Patel, B. Pardhi, S. K. Sahu, and M. K. Singh, "Characterization of Brinell Hardness , Impact Toughness and Sliding Wear Resistance Properties of Al5Mg5Zn/WO3-p Metal Matrix Composite," imanager's J. Mater. Sci., vol. 7, no. 4, pp. 22-29, 2020.

[11] M. B. Karamis, A. Tasdemirci, and F. Nair, "Failure and tribological behaviour of the AA5083 and AA6063 composites reinforced by $\mathrm{SiC}$ particles under ballistic impact," Compos. Part A Appl. Sci. Manuf., vol. 34, no. 3, pp. 217-226, 2003. https://doi.org/10.1016/S1359835X(03)00024-1

[12] M. Patel, M. K. Singh, and S. K. Sahu, "Abrasive Wear Behaviour of Sand Cast $\mathrm{B}_{4} \mathrm{C}$ Particulate Reinforced AA5052 Metal Matrix Composite," in Innovative Product Design and Intelligent Manufacturing Systems, 2020, pp. 359-369. https://doi.org/10.1007/978-981-152696-1 35

[13] M. Patel, B. Pardhi, M. Pal, and M. K. Singh, "SiC Particulate Reinforced Aluminium Metal Matrix Composite,” Adv. J. Grad. Res., vol. 5, no. 1, pp. 8-15, 2019. https://doi.org/10.21467/ajgr.5.1.8-15

[14] M. Patel, A. Kumar, S. K. Sahu, and M. K. Singh, "Mechanical Behaviors of Ceramic Particulate Reinforced Aluminium Metal Matrix Composites - A Review," Int. Res. J. Eng. Technol., vol. 7, no. 1, pp. 201-204, 2020.

[15] D. Sujan, Z. Oo, M. E. Rahman, M. A. Maleque, and C. K. Tan, "Physio-mechanical properties of aluminium metal matrix composites reinforced with $\mathrm{Al} 2 \mathrm{O} 3$ and $\mathrm{SiC}$ Physio-mechanical Properties of Aluminium Metal Matrix Composites Reinforced with Al 2 O 3 and SiC," Int. J. Eng. Appl. Sci., vol. 6, pp. 288-291, 2012.

[16] M. Patel, B. Pardhi, S. K. Sahu, A. Kumar, and M. K. Singh, "Evaluation of Hardness, Toughness and Sliding Wear Resistance after Replacing $\mathrm{Zn}$ into $\mathrm{SiC}$ in A15Mg5Zn/3WO - p Metal Matrix Composite," Int. J. Res. Eng. Appl. Manag., vol. 05, no. 03, pp. 106-110, 2019.

[17] U. Cocen and K. Onel, "Ductility and strength of extruded SiCp/aluminium-alloy composites," Compos. Sci. Technol., vol. 62, pp. 275-282, 2002. https://doi.org/10.1016/S0266-3538(01)00198-1

[18] Y. Sahin, "Preparation and some properties of SiC particle reinforced aluminium alloy composites," Mater. Des., vol. 24, pp. 671-679, 2003. https://doi.org/10.1016/S0261-3069(03)00156-0

[19] I. M. El-Galy, M. H. Ahmed, and B. I. Bassiouny, "Characterization of functionally graded Al-SiCp metal matrix composites manufactured by centrifugal casting," Alexandria Eng. J., vol. 56, no. 4, pp. 371-381, 2017. https://doi.org/10.1016/j.aej.2017.03.009

[20] B. Venkataraman and G. Sundararajan, "The sliding wear behaviour of Al-SiC particulate composites-I.
Macrobehaviour," Acta Mater., vol. 44, no. 2, pp. 451460, 1996. $\quad$ https://doi.org/10.1016/13596454(95)00217-0

[21] T. Ozben, E. Kilickap, and C. Orhan, "Investigation of mechanical and machinability properties of SiC particle reinforced Al-MMC," J. Mater. Process. Technol., vol. 198, no. 1-3, pp. 220-225, 2008. https://doi.org/10.1016/j.jmatprotec.2007.06.082

[22] T. B. Rao, "An experimental investigation on mechanical and wear properties of Al7075/SiCp composites: effect of SiC content and particle size," J. Tribol., vol. 140, no. 3, p. 031601, 2017. https://doi.org/10.1115/1.4037845

[23] S. Ozden, R. Ekici, and F. Nair, "Investigation of impact behaviour of aluminium based $\mathrm{SiC}$ particle reinforced metal-matrix composites," Compos. Part A Appl. Sci. Manuf., vol. 38, pp. 484-494, 2007. https://doi.org/10.1016/j.compositesa.2006.02.026

[24] K. L. Meena, A. Manna, and S. S. Banwait, "An analysis of mechanical properties of the developed $\mathrm{Al} / \mathrm{SiC}$ MMC's," Am. J. Mech. Eng., vol. 1, no. 1, pp. 14-19, 2013.

[25] A. Dolatkhah, P. Golbabaei, M. K. B. Givi, and F. Molaiekiya, "Investigating effects of process parameters on microstructural and mechanical properties of Al5052/SiC metal matrix composite fabricated via friction stir processing," Mater. Des., vol. 37, pp. 458464, 2012. doi:10.1016/j.matdes.2011.09.035

[26] E. H. Dix, JR, W. A. Anderson, and M. B. Shumaker, "Influence of service temperature on the resistance of wrought aluminum-magnesium alloys to corrosion," Corros. Natl. Assoc. Corros. Eng., vol. 15, no. 2, pp. 1926, 1959. https://doi.org/10.5006/0010-9312-15.2.19

[27] K. V. Mahendra and K. Radhakrishna, "Characterization of stir cast $\mathrm{Al}-\mathrm{Cu}$-(fly ash $+\mathrm{SiC}$ ) hybrid metal matrix composites," J. Compos. Mater., vol. 44, no. 8, pp. 9891005, 2010. https://doi.org/10.1177/0021998309346386

[28] U. K. Annigeri and G. B. Veeresh Kumar, "Method of stir casting of aluminum metal matrix composites: A review," Mater. Today Proc., vol. 4, no. 2, pp. 11401146, 2017. https://doi.org/10.1016/j.matpr.2017.01.130

[29] D. J. Lloyd, H. Lagace, A. McLeod, and P. L. Morris, "Microstructural aspects of aluminium-silicon carbide particulate composites produced by a casting method," Mater. Sci. Eng. A, vol. 107, pp. 73-80, 1989. https://doi.org/10.1016/0921-5093(89)90376-6

[30] J. B. Rao, D. V. Rao, I. N. Murthy, and N. Bhargava, "Mechanical properties and corrosion behaviour of fly ash particles reinforced AA 2024 composites," J. Compos. Mater., vol. 42, no. 12, pp. 1393-1404, 2011. https://doi.org/10.1177/0021998311419876

[31] A. S. T. M. E92-82, "Standard Test Method for Vickers Hardness of Metallic Materials," Am. Soc. Test. Mater. 100 Barr Harb. Dr., West Conshohocken, PA 19428 Repr. from Annu. B. ASTM Stand. Copyr. ASTM, 1997.

[32] R. Raj, "Compression test of aluminium alloy at different strain rate," National Institute of Technology ROURKELA, 2013.

[33] D. Sujan, Z. Oo, M. E. Rahman, M. A. Maleque, and C. K. Tan, "Physio-mechanical properties of aluminium metal matrix composites reinforced with $\mathrm{Al} 2 \mathrm{O} 3$ and SiC,” Int. J. Eng. Appl. Sci., vol. 6, pp. 288-291, 2012.

[34] A. H. Idrisi, V. D. Singh, and V. Saxena, "Development and testing of Al5083 alloy reinforced by $\mathrm{SiC}$ particles," Int. J. Sci. Res. Eng. Technol., vol. 2, no. 11, pp. 697704, 2014. 
Murlidhar Patel et al., J. Mod. Mater.; Vol. 7, Issue 1, pp: 26-36, 2020

[35] M. Patel, S. K. Sahu, M. K. Singh, and A. Kumar, "Sliding Wear Behavior of Particulate Reinforced Aluminium Metal Matrix Composites," Int. J. Eng. Res. Curr. Trends, vol. 2, no. 3, pp. 8-13, 2020.

[36] M. Patel, P. K. Sen, and G. Sahu, "A Review on Noise Sources and Methods of Reduction of Noise in Diesel Engines,” Int. J. Eng. Sci. Res. Technol., vol. 1, no. 4, pp. 601-607, 2015.

[37] M. Patel, P. K. Sen, G. Sahu, R. Sharma, and S. Bohidar, “A Review on Ram Jet Engine," Int. J. Res., vol. 2, no. 11, pp. 131-136, 2015.

Publish your books with AIJR publisher-

* Publish with ISBN and DOI.

* Publish Thesis/Dissertation as Monograph.

* Publish Book Monograph.

* Publish Edited Volume/ Book.

* Publish Conference Proceedings

* Retain full copyright of your books.

Submit your manuscript at books.aijr.org
Publish your research article in AIJR journals-

1. Online Submission and Tracking

2. Peer-Reviewed

3. Rapid decision

4. Immediate Publication after acceptance

5. Articles freely available online

6. Retain full copyright of your article.

Submit your article at journals.aijr.in 